\title{
Effects of beverage alcohol taxes and prices on drinking: a meta-analysis of 1003 estimates from 112 studies
}

Article

Accepted Version

Wagenaar, A. C., Salois, M. J. and Komro, K. A. (2009) Effects of beverage alcohol taxes and prices on drinking: a metaanalysis of 1003 estimates from 112 studies. Addiction, 104 (2). pp. 179-190. ISSN 0965-2140 doi:

https://doi.org/10.1111/j.1360-0443.2008.02438.x Available at https://centaur.reading.ac.uk/17960/

It is advisable to refer to the publisher's version if you intend to cite from the work. See Guidance on citing.

To link to this article DOI: http://dx.doi.org/10.1111/j.1360-0443.2008.02438.x

Publisher: Wiley-Blackwell

All outputs in CentAUR are protected by Intellectual Property Rights law, including copyright law. Copyright and IPR is retained by the creators or other copyright holders. Terms and conditions for use of this material are defined in the End User Agreement.

www.reading.ac.uk/centaur 
Central Archive at the University of Reading

Reading's research outputs online 


\title{
Effects of Beverage Alcohol Price and Tax Levels on Drinking: A Meta-analysis of 1003 Estimates from 112 Studies
}

\author{
Short Title: Meta-analysis of Alcohol Price
}

\author{
Alexander C. Wagenaar, PhD* \\ Matthew J. Salois, PhD \\ Kelli A. Komro, PhD
}

\author{
University of Florida \\ College of Medicine \\ Dept of Epidemiology \& Health Policy Research \\ 1329 SW $16^{\text {th }}$ St. Rm. 5130 Box 100177 \\ Gainesville, FL 32610-0177 U.S.A.
}

*Corresponding Author: Alexander C. Wagenaar, Professor, University of Florida, College of Medicine, Department of Epidemiology and Health Policy Research, 1329 SW $16^{\text {th }}$ Street, Rm. 5130; P.O. Box 100177; Gainesville, FL 32610-0177 USA. Tel: (352) 265-0111 ext. 85684; Fax: (352) 265-8047; E-mail: wagenaar@gmail.com

Page Count: 39 (Including Appendix)

Word Count: 4179

Conflicts of Interest: None 


\title{
Effects of Beverage Alcohol Price and Tax Levels on Drinking: A Systematic Review and Meta-analysis of 1003 Estimates from 112 Studies
}

\author{
Alexander C. Wagenaar, PhD, Matthew J. Salois, MA \& Kelli A. Komro, MPH, PhD
}

\section{Abstract}

Aims. We conducted a systematic review of studies examining relationships between measures of beverage alcohol tax or price levels and alcohol sales or self-reported drinking. A total of 112 studies of alcohol tax or price effects were found, containing1003 estimates of the tax/price $\rightarrow$ consumption relationship.

Design. Studies included analyses of alternative outcome measures, varying subgroups of the population, several statistical models, and use different units of analysis. Multiple estimates were coded from each study, along with numerous study characteristics. Using reported estimates, standard errors, t-ratios, sample sizes and other statistics, we calculated the partial correlation for the relationship between alcohol price or tax and sales or drinking measures for each major model or subgroup reported within each study. Random-effects models were used to combine studies for inverse variance weighted overall estimates of the magnitude and significance of the relationship between alcohol tax/price and drinking.

Findings. Simple means of reported elasticities are -0.46 for beer, -0.69 for wine, -0.80 for spirits. Meta-analytic results document the highly significant relationships $(\mathrm{p}<.001)$ between alcohol tax or price measures and indices of sales or consumption of alcohol (aggregate-level $r=$ -0.17 for beer, -0.30 for wine, -0.29 for spirits, and -0.44 for total alcohol). Price/tax also significantly affects heavy drinking (mean reported elasticity $=-0.28$, individual-level $r=-0.01$, $p<.01$ ), but the magnitude of effect is smaller than effects on overall drinking. 
Conclusions. A large literature establishes that beverage alcohol prices and taxes are inversely related to drinking. Effects are large compared to other prevention policies and programs. Public policies that raise prices of alcohol are an effective means to reduce drinking.

Keywords: alcohol, price, tax, systematic review, meta-analysis 


\section{INTRODUCTION}

There is a large literature over the past several decades on the relationship between beverage alcohol tax and price levels and alcohol sales or consumption measures. Excise and sales taxes represent the most widespread public policy affecting retail price of alcohol; some studies measure prices directly, and many use tax rates as a surrogate measure for price, since differences in price across geographic areas are largely due to differing tax rates. Studies differ substantially in terms of methodological quality—some using longitudinal designs and others are simple cross-sectional surveys, some carefully controlled with comparison groups and covariates, others more rudimentary analyses. Economists, using contemporary econometric modeling methods, conduct a majority of these studies, but a substantial minority of studies are conducted by scientists in other disciplines related to health or social sciences. Beyond obvious differences in methodological quality from study to study, even studies most would consider of high quality vary in many details of measurement, jurisdiction studied, and statistical approach, and study authors' interpretation of a given pattern of empirical findings varies substantially across papers.

Several narrative reviews of this extensive literature have appeared. Early reviews were conducted by Ornstein [1] and Ornstein \& Levy [2]. They suggest best estimates of price elasticities for beer, wine and spirits to be $-0.30,-1.00$ and -1.50 , respectively. Leung and Phelps [3] report that studies using individual-level data tend to obtain larger (i.e., more elastic) demand estimates than aggregate-level studies. Also, they report that results from aggregate-level studies are sensitive to the choice of functional form in the demand model specification. Manning, et al. [4] examine several aggregate-level studies on the effects of excise taxes on alcohol consumption, reporting a range of price elasticities between -0.80 and -2.0 for spirits; -0.64 and - 
1.0 for wine; -0.25 and +0.24 for beer; and -0.50 and -1.6 for overall alcohol consumption. Grossman, et al. [5] reviewed research on price effects of alcohol on consumption by youth, comparing different individual and aggregate data sets between 1974 and 1989. They conclude that both frequent and heavy consumption of alcohol by youth are negatively correlated with alcohol price. Edwards et al. [6] tabulated 52 sets of elasticity estimates for beer, wine, and distilled spirits for 18 countries across different time periods. The elasticities vary substantially across studies, countries, time, beverage type, and whether the elasticity estimate is elastic, unit elastic, or inelastic. But note that, all, with the exception of one estimate, are negative. Cook and Moore [7] summarized the economic literature on drinking and associated outcomes, concluding that the demand for alcohol is downward sloping, indicating excise taxes can be used as an effective alcohol-control policy. Chaloupka, et al. [8] reviewed studies that examine price effects on consumption and alcohol-related outcomes for youth. They conclude that frequency of youth drinking and probability of heavy drinking can be decreased by an increase in beer excise taxes.

Only two meta-analyses have been published, both of which have different goals and use a fundamentally different approach than our study reported here. Fogarty [9] took alcohol elasticity estimates from a review by Edwards, et al. [6] which only included studies through 1992; Gallet [10] includes 132 studies of alcohol price, income or advertising elasticities through 2003. The two studies $[9,10]$ report illuminating results on possible effects of study characteristics (i.e., data used, model specification, estimation method) on estimated elasticity. However, neither takes into account the variances attached to each estimate coming from the primary studies, implicitly weighting each estimate equally. In contrast, we explicitly cumulate the evidence by weighting each estimated effect by the inverse of its variance. Gallet [10] used dummy variables to account for study-author effects, while we used random effects models 
which into account the second-level variance at the study level in assessing the precision of the cumulative estimates. In short, the Fogarty and Gallet studies come from an econometric tradition and report results from simple OLS regressions of study characteristics on reported elasticity. The present study comes out of the systematic review and meta-analysis traditions in epidemiology and the social sciences, where evidence for an underlying relationship of theoretical and practical significance is cumulated across studies based on the point estimates and estimated variances from individual studies using multi-level random effects models.

\section{METHODS}

The core independent variable is measured in this literature in two main ways: direct measurement of retail price of alcoholic beverages, or use of tax rates as an indicator or surrogate for prices, since cross-jurisdiction and longitudinal variability in prices is heavily influenced by state/province/country tax rates on alcohol. As Kenkel [11] notes, economic theory predicts taxes will be fully passed through to consumers, given a competitive environment with constant marginal costs of production, and such a one-to-one pass through is a "standard assumption" in most of the research on alcohol taxes or prices. While empirical evidence is fairly limited, data indicate that taxes are passed through to prices, typically at pass-through rates of one to two (e.g., a 10 cent increase in tax produces a 10 to 20 cent increase in price; [11-13]). For the present meta-analysis, we included studies that use tax rates as a price indicator and those that measured retail prices directly, given the high correlation between the two. Nevertheless, the issue of potentially varying pass-through rates depending on local market and regulatory conditions must be noted in projecting tax policy effects. Finally, many jurisdictions control alcohol prices via 
mechanisms other than taxes (e.g., distribution monopolies, licensing fees); effects of such nontax regulations (which in some cases affect prices) are not included in the current meta-analysis.

The core dependent variables for the current study are: (1) measures of the quantity, prevalence, or frequency of alcohol sold or consumed, stratified by beverage type when available (beer, wine, spirits), and (2) measures of heavy consumption or intoxication.

Data for this meta-analytic study are quantitative estimates of the magnitude or strength of these relationships, and estimates of the variability or error of those estimates, all coming from previously completed studies in the literature. Thus, major components of the project were identifying and obtaining the original study reports, calculating and coding multiple effect sizes and standard errors along with numerous population and other characteristics from each study, and statistically aggregating across all resulting estimates of the underlying relationships of conceptual interest. Each of these is now addressed in more detail.

\section{Data Collection--Literature Search}

A comprehensive literature search was conducted by a doctoral-level graduate student with expertise in econometric and statistical methods. Searches were conducted of nine databases to identify studies of interest: AgEcon Search (1960-present), Blackwell-Synergy (1879-present), EBSCO Host, which encompasses EconLit (1969-present), Academic Search Premier (1922present), Business Source Premier (1922-present), and PsychInfo (1967-present), JSTOR (1838present), MEDLINE (1950-present), Springer (1992-present), ScienceDirect (1823-present), ISI Web of Knowledge (1900-present), and Wiley (1961-present). The entire record for each document was included in each search; thus, any record with any search term in the title, keywords, subject headings, descriptors or abstract fields would be identified. The set of search terms that was used for each database is as follows, where $*$ is the truncation indicator to include 
all forms of the root word: [(tax OR taxes OR taxation OR cost OR cost* OR price OR prices) AND (alcohol* OR drinking OR liquor OR drunk* OR beer OR wine OR spirits OR malt beverage*)]. The search process, particularly for older papers not in current on-line databases, was supplemented with an extensive reprint file of alcohol tax papers maintained over the last 30 years by the first author. Moreover, "snowball" sampling, using reference lists from each identified paper, was used to locate additional studies. The original document for each publication was obtained and reviewed for relevance and content. Studies were excluded from analysis if they: (1) are duplicate publications of a single study/dataset (keeping most recent); (2) are empirical studies but do not provide sufficient data for calculating some form of numeric estimate of effect and estimate of its standard error; (3) are commentaries, legal reviews, literature reviews, or otherwise report no new data; or (4) are not written in English. The above procedures produced 112 papers containing 1003 separate empirical estimates of the relationship between alcohol taxes/prices and drinking (see the Appendix for the complete list of citations).

Despite extensive procedures to locate relevant studies, there are always limitations to the search strategy. First, analyses were exclusively based on reports published in English. This was simply a practical consideration; however, it could potentially bias the results of the metaanalyses [14-16]. Research has shown that the proportion of studies with statistically significant results is higher among reports published in English compared with those in other languages [1618]. Thus, exclusion of non-English studies could lend to inflated meta-estimates of effect, but note that one study found the inflation in effect size due to English-language restriction to be only $2 \%$ [19]. Second, publication bias (or, more generally, small-study bias) is always a threat to the validity of a meta-analysis [20-22]. Statistically significant findings are more likely to be published than those that are not significant [14, 20-22], with one estimate suggesting that the 
odds of publication are 2 to 4 times greater when results are statistically significant [14]. Thus, it is possible that a substantial number of studies with non-significant effects remain unpublished. Excluding these unpublished studies may introduce an upward bias into obtained effect estimates [23]. On the other hand, Sutton et al. [24] empirically examined publication bias across metaanalyses; while $54 \%$ of meta-analyses studied were determined to have had missing studies, these biases "did not affect the conclusions" of the meta-analyses. We did not exclude available unpublished studies, but we also did not implement extensive searching for difficult-to-find unpublished studies. While clearly beneficial, inclusion of explicit search procedures for such "fugitive" literature is prohibitively expensive. Methodologically, this creates a risk the results are subject to publication bias.

\section{Coding-Determining Effect Sizes and their Precision}

Meta-analysis aggregates and compares findings from different research studies, therefore it is necessary that those findings are both conceptually comparable and configured in a similar statistical form [25]. The first criterion requires that included studies deal with the same constructs and relationships in order for meaningful comparisons to be made. This can be problematic, because what is deemed conceptually comparable may differ across analysts, a particular issue when scientists in different disciplines analyze the same set of studies. In the present case, all the studies were conceptually very similar, examining relationships of identical concepts. Nevertheless, there is considerable variability in specific measures, research designs, and statistical models. For study findings to be meaningfully compared (and statistically aggregated and analyzed), they must lend to calculation of a single uniform effect-size metric that is appropriate to the conceptual nature of the relationship in the research findings and the statistical forms reported in the literature. Numerous population and study characteristics were 
coded, including multiple outcome measures (eg., beer, wine, spirits, if reported separately), age group, research design, level of analysis, sample design and size, and statistical methods.

Most important and complex is the coding of an effect size in a standardized comparable metric across all studies that represents both the direction and magnitude of the difference or relationship for each study finding. The individual studies identified used diverse research designs and statistical methods. Nevertheless, almost all provide results from some sort of regression equation showing estimated coefficients and standard errors or other statistics that indicate, or provide a basis for estimating, the standard error (e.g., a t-ratio or confidence interval). Multiple estimates from each study were coded, including multiple subgroups, multiple follow-ups, and from multiple statistical models for each subgroup. The measure of effect, its standard error, the analysis sample size, and the effect's significance level were coded for each separate estimate. For studies that report $p$-value cut-off values ( 0.05 , for example) but not exact values, we (conservatively) assigned the value 0.05 , even though the (unknown) true exact value was less than .05 .

\section{Statistical Analyses}

Based on statistics reported in each study, and using conversion formulae from the meta-analysis literature programmed in Comprehensive Meta-analysis 2.0 software (CMA; [26]), we estimated a standardized effect size $r$ for each separate estimate of the underlying relationship of interest,

where $\left.r=\sqrt{t^{2} /\left(t^{2}+(N-2)\right.}\right)$ and its associated Fisher's Z given by $E S_{Z_{i}}=.5 \log _{e} \mathbf{I}+r / 1-r_{-}^{-}$. In addition to standardized effect size estimates, the standard errors of those estimates were calculated as $S E_{z_{i}}=1 / \sqrt{n-3}$ and $S E_{r}=\left(1-r^{2}\right) * S E_{z}$. Note that the $r$ estimates are also interpretable as the standardized slope of the relationship between price/tax and consumption. 
At a broad level, statistical analyses involved combining diverse individual estimates of effect into a single (or small number of) meta-estimates of effect in a common metric, and standard error of that effect. We examined heterogeneity of effects and conducted sensitivity and robustness analyses to evaluate consistency of estimates across study characteristics, and risks to the meta-estimates due to publication bias and potential non-representativeness of the sample studies.

Combining the individual effect sizes into a single meta-estimate of effect involved several steps. First, we identified sets of statistically independent (e.g., separate youth and adult samples, separate states, etc.) and non-independent (e.g., multiple estimation models using the same population or sample) estimates. Intra-study effect sizes based on the same study population or sample were averaged such that only one value contributed to the meta-analyses [25]. Inverse variance weighting methods were applied to each resulting (independent) effect size, where the weight applied is $w_{i}=1 / v_{i}$, with $v_{i}=S E_{E S_{i}}^{2}$. Second, we evaluated the effect size distribution for outliers, to determine the need for trimming or Windsorizing (results for both the full analyses and trimmed models without outlier studies are shown in Tables 1-5). We computed the weighted mean effect size for each subgroup (based on study characteristics) by $\overline{E S}=\Sigma\left(w_{i} E S_{i}\right) / \Sigma w_{i}$, where $E S_{i}$ are the values of the effect size statistic used (here $r$ or Fisher's Z), $w_{i}$ is the inverse variance weight for each effect size $i$, and $i$ is equal to 1 to $k$, with $k$ being the number of effect estimates.

Homogeneity tests within and across subgroups based on study characteristics were based on the $Q$ statistic, $Q=\sum w_{i}\left(E S_{i}-\overline{E S}\right)^{2}$, where $E S_{i}$ is the individual effect size for $i=1$ to $k, \overline{E S}$ is the weighted mean effect size over the $k$ effect sizes, and $w_{i}$ is the individual weight for $E S_{i} . Q$ 
is distributed as a chi-square with $k-1$ degrees of freedom [27]. A statistically significant $Q$ indicates a heterogeneous effect size distribution [28].

Given our initial review of this literature and the diversity found, we expected statistically significant (residual) study-level heterogeneity, which was confirmed by significant $Q$-statistics. Therefore, we used random- (as opposed to fixed-) effects models when estimating average effects and their precision. Random-effects models are more conservative, producing wider confidence bounds around the meta-estimates of effect. Random effects modeling means that the variance for each effect size is a function of both underlying subject-level sampling error and random, between-studies variance component [25], such that $v_{i}^{*}=v_{i}+\tau^{2}$, where $v_{i}$ is the initial subject-level sampling error and $\tau^{2}$ is the random variance component, estimated by $\tau^{2}=Q-(k-1) / \sum w_{i}-\left(\sum w_{i}^{2} / \sum w_{i}\right)$, where $Q$ is the value of the homogeneity test, $k$ is the number of effect sizes, and $w_{i}$ is the inverse variance weight for each effect size defined under the fixed-effects model. The inverse variance weight applied to each effect size thus becomes $w_{i}^{*}=1 / v_{i}^{*}$ and the mean effect size is recomputed. Next, we computed the standard error of the mean effect size, $S E_{\overline{E S}}=\sqrt{1 / \Sigma w_{i}}$, where $w_{i}$ (or $w_{i}^{*}$ for random effects models) is the inverse variance weight associated with effect size $i$ with $i=1$ to $k$ effect sizes included in the mean [27]. We constructed confidence intervals and tested the significance of each mean effect size, where a 95\% confidence interval is $\overline{E S} \pm Z_{(95)}\left(S E_{\overline{E S}}\right)$ and the significance of the mean effect size can be obtained with a $Z$-test as $z=\overline{|E S|} / S E_{\overline{E S}}$.

There is a debate in the meta-methods literature on whether direct meta-analyses of the partial $r$ estimate from each study is best, or meta-analyses of the Fisher's $Z$ transform of the $r$ 's is preferred to avoid possible bias in calculation of the standard error of $r$. For completeness, we 
conducted all analyses twice, once using $r$ values as inputs, and again using Fisher's Z's.

However, the bias is known to be smaller than rounding error when study n's are over 40 [29]; consistent with expectations, we found very little difference in results between the two, and our presentation here is based on analyses of $r$ 's instead of Fisher's Z's.

\section{RESULTS}

First, we present results from studies which examined effects of alcohol price or tax on general alcohol consumption, not stratified by beverage type. The simple mean of 91 elasticity estimates reported is -0.51 . Because the underlying population variance of aggregate-level studies is considerably smaller than that of individual-level studies, we examined effect sizes separately for the two types of study. The inverse weighted overall partial $r$ for 24 studies that examined these relationships using aggregate-level data (most often at the state/province level) is -0.44 , which is highly significant $(Z=7.55, p<.01$; Table 1$)$. Examination of the top panel of Table 1 shows how strong this evidence is - all but one study found an inverse relationship, and 19 of the 24 studies show a significant inverse effect. At the individual level, the effect size in terms of standard deviation units is considerably smaller, as one would expect given the larger variation across individuals than across states/provinces, but the evidence remains very strong, with an overall $r=-0.06, Z=-4.27, \mathrm{p}<.01$ (second panel of Table 1). Removing one outlier [30] has little effect on the overall results.

$* * * * * * * * * * * *$

\section{INSERT TABLE 1 HERE}

$* * * * * * * * * * * *$

The simple mean beer price/tax elasticity across 105 reported estimates in the 47 identified studies is -0.46 . Variance weighted overall partial $r$ estimate from 40 aggregate-level 
studies is $-0.17(Z=-6.91 ; p<.01$; Table 2$)$. All but five studies report an inverse relationship, and 11 of the 40 studies report an effect that is not statistically significant at the study level (using $p<.05$ criterion). Only seven individual-level studies specifically of price/tax effects on beer consumption were found. All seven report an inverse relationship, but four of the seven are not significant at the individual study level. Despite this, the seven studies as a group clearly show a significant inverse effect, with an overall inverse variance weighted $r=-0.12, Z=-2.37$, $\mathrm{p}=.02$.

$* * * * * * * * * * * *$

\section{INSERT TABLE 2 HERE}

$* * * * * * * * * * * *$

Thirty-two studies examined the effects of tax or price on wine consumption (mostly overlapping with authors who also report effects for beer and spirits). The simple mean of 93 elasticities reported is -0.69 . All but five studies report an inverse relationship, with five of the 32 not significant at the study level (using $p<.05$ criterion). Five of six individual-level studies similarly report an inverse relationship, although half are not significant at the study level. However, the meta-estimated effect across the seven studies is clearly significant $(r=-0.30, Z=-$ 8.03, $p<.01$; Table 3).

$* * * * * * * * * * * *$

\section{INSERT TABLE 3 HERE}

$$
* * * * * * * * * * * *
$$

Forty-five aggregate-level studies of alcohol tax/price effects on spirits consumption have appeared, reporting 103 elasticity estimates with an overall simple mean of -0.80 . Thirty-nine of the 45 studies report an inverse effect estimate, and 11 of the 45 studies report no statistically 
significant relationship. Combining all the estimates produces an estimated partial $r=-0.29(Z=$ -9.23, $p<.01)$. Similar results are found for the six individual-level studies $(r=-0.10, Z=-2.52$, $p<.01$; Table 4).

$* * * * * * * * * * * *$

\section{INSERT TABLE 4 HERE}

$* * * * * * * * * * * *$

Finally, ten studies of the effects of alcohol prices or taxes on various indicators of heavy drinking have appeared, all studies are inherently at the individual level, since sales data do not differentiate by drinking status. The simple mean of the ten elasticities reported is -0.28 . All but one study found an inverse effect, and eight of the ten studies found statistically significant effects at the study level. The meta-estimate of effect across the ten studies is $r=-0.01$ ( $Z=-$ 2.54, $p<.01$; Table 5).

$* * * * * * * * * * * *$

\section{INSERT TABLE 5 HERE}

\footnotetext{
$* * * * * * * * * * * *$
}

Results are summarized in Figure 1 for the aggregate-level studies, and Figure 2 for the individual-level studies. The differing magnitude of estimated effects between the two types of studies is a consequence of a statistical artifact. The $r$ estimates reported here represent the amount of change in standard deviation units in alcohol sales/consumption associated with a one standard deviation change in price/tax. Aggregating the population into larger units (such as cities, states or countries) substantially lowers the variability of the measure, since individual differences are "averaged out" (a longstanding known effect in sociology; see Blalock, Jr. [31], p. 106). 
$* * * * * * * * * * * *$

INSERT FIGURES $1 \& 2$ HERE

$* * * * * * * * * * * *$

\section{DISCUSSION}

Results confirm previous reviews of this literature, but extend those results in important ways. The literature we analyzed contains 1003 separate estimates of the underlying conceptual relationship of interest. Narrative reviews inherently take short-cuts, often including only "major" studies, or only studies in the reviewer's discipline, or only recent studies. Narrative reviews often summarize the conclusions of the study authors, not necessarily the empirical results reported in data tables. And reviews often give disproportionate attention to a small number of studies with divergent results. The meta-analyses reported here demonstrate the statistically overwhelming evidence of effects of alcohol prices on drinking. Price affects drinking of all types of beverages, and across the population of drinkers from light drinkers to heavy drinkers. We know of no other preventive intervention to reduce drinking that has the numbers of studies and consistency of effects seen in the literature on alcohol taxes and prices.

A frequent criticism of meta-analyses is that they combine "apples and oranges," that is, combine results from studies that differ in important ways. Our sample of studies is conceptually very well-integrated, but diverse in terms of units analyzed, treatments (i.e., size of tax or price change evaluated), outcome measures, settings, time, and specific statistical models. On the last issue, a purist would argue that results from models with differing sets of covariates cannot be combined with the methods described here (and moreover, methods to address this issue have not yet been developed). Optimally, we would have available identical (bivariate) estimates of effect from all studies, but such estimates are not available in the published papers. We are not 
alone with this problem. Diversity in model covariates is fairly common in published metaanalyses, and does not prevent investigators from statistically aggregating the evidence, even though statistical theory that is the basis of meta-analyses was originally based on uniform bivariate estimates (and implicitly assume all studies used the same research design and statistical method). We used random-effects (rather than fixed-effects) models to combine studies, which help take into account such study-level variability, permitting a relaxation of the assumption that all studies are estimating the exact same underlying effect. Moreover, our use of random effects models is deemed a conservative approach, since estimated confidence intervals around point estimates are larger for random-effects models than fixed-effect models. Importantly, future studies are warranted that statistically model potential explanations of differences in estimated effect sizes across studies, and that examine price/tax effects on a range of relevant health and social outcomes. We are continuing such analyses, with meta-analyses of price/tax effects on morbidity and mortality outcomes currently in progress.

The meta-analyses reported here and much of the economic literature on alcohol may give the impression that price elasticities are somehow inherent properties of the different beverages studied. But results across studies suggest that the magnitude of price effects varies across groups, situations, and times. At the most basic level, price interacts with income in affecting consumption. Perhaps the effects of price/tax are not linear, but are characterized by effect thresholds such that effects qualitatively differ in communities or societies with very high or very low levels of consumption. All estimates of tax and price effects also reflect particular meanings and uses of alcoholic beverages across diverse social and cultural environments, and tax and price policies likely interact with a whole web of individual, community and societal influences on drinking behavior. 
Finally, the effect sizes reported here are large. Cohen [32], one of the "founding fathers" of meta-analyses, suggested $d$ (standardized difference) effect sizes under 0.20 are small, 0.50 are medium, and $>0.80$ are large; equivalent effects in terms of $r$ mean a small effect is 0.10 , medium is 0.24 and large is 0.37 . Lipsey \& Wilson [33] report from a study of over 300 metaanalyses of diverse behavioral and educational interventions showed a median effect size equivalent to $r=0.24$. At the aggregate level where tax policy as a preventive intervention operates, the estimated effect sizes reported here for wine, spirits and overall alcohol consumption are clearly above such reported median level of prevention effectiveness. Given (1) very low cost of adjusting alcohol tax policies to achieve substantial prevention benefits, (2) the global burden of disease and injury due to alcohol consumption [34, 35], and (3) high levels of fiscal and social costs of alcohol-related problems [36-38], the magnitudes of effect that are clearly established in the extant literature on alcohol price effects are noteworthy.

\section{Acknowledgements}

This study was funded in part by the Robert Wood Johnson Foundation. Findings and conclusions are solely the authors. Special thanks to Amy L. Tobler for assistance with manuscript preparation.

\section{References}

[1] Ornstein S.I. Control of alcohol-consumption through price increases. Journal of Studies on Alcohol 1980; 41: 807-18.

[2] Ornstein S.I., Levy D. Price and income elasticities and the demand for alcoholic beverages. In: Galanter M., ed. Recent Developments in Alcoholism. New York: Plenum; 1983. p. 303-45. 
[3] Leung S., Phelps C.E. My kingdom for a drink...? A review of estimates of the price sensitivity of demand for alcoholic beverages. In: Hilton M.E., Bloss G., eds. Economics and the Prevention of Alcohol-Related Problems NIAAA Research Monograph No 25 NIH Pub No 93-3513. Bethesda, MD: National Institutes of Health; 1993. p. 1-31.

[4] Manning W.G., Blumberg L., Moulton L.H.. The demand for alcohol - the differential response to price. Journal of Health Economics 1995; 14: 123-48.

[5] Grossman M., Chaloupka F.J., Saffer H., Laixuthai A. Effects of alcohol price policy on youth: a summary of economic research. Journal of Research on Adolescence 1994; 4: 347-64.

[6] Edwards G., Anderson P., Babor T.F., Casswell S., Ferrence R., Giesbrecht N., et al. Alcohol policy and the public good. New York, NY: Oxford University Press; 1994.

[7] Cook P.J., Moore P.J. Alcohol. Cambridge, MA: National Bureau of Economic Research; 1999.

[8] Chaloupka F.J., Grossman M., Saffer H. The effects of price on alcohol consumption and alcohol-related problems. Alcohol Research \& Health 2002; 26: 22-34.

[9] Fogarty J. The nature of the demand for alcohol: understanding elasticity. British Food Journal 2006; 108: 316-32.

[10] Gallet C.A. The demand for alcohol: a meta-analysis of elasticities. The Australian Journal of Agricultrual and Resource Economics 2007; 51: 121-35.

[11] Kenkel D.S. Are alcohol tax hikes fully passed through to prices? Evidence from Alaska. American Economic Review 2005; 95: 273-7. 
[12] Cook P.J. The effect of liquor taxes on drinking cirrhosis and auto accidents. In: Moore M.H., Gerstein D., eds. Alcohol and Public Policy: Beyond the Shadow of Prohibition. Washington, DC: National Academy Press; 1981.

[13] Young D.J., Bielinska-Kwapisz A. Alcohol taxes and beverage prices. National Tax Journal 2002; 55: 57-73.

[14] Egger M., Dickersin K., Smith G.D. Problems and limitations in conducting systematic reviews. In: Egger M., Smith G.D., Altman D.G., eds. Systematic Reviews in Health Care: Meta-analysis in Context. London: BMJ Books; 2001.

[15] Gregoire G., Derderian F., LeLorier J. Selecting the language of the publications included in a meta-analysis: is there a Tower of Babel bias? Journal of Clinical Epidemiology 1994; 48: 159-163.

[16] Moher D., Fortin P., Jadad A.R., et al. Completeness of reporting of trials published in languages other than English: implications for conduct and reporting of systematic reviews. Lancet 1996; 347: 363-366.

[17] Egger M., Zellweger-Zahner T., Schneider M., Junker C., Lengeler C., Antes G. Language bias in randomised controlled trials published in English and German. Lancet 1997; 350: 326-329.

[18] Sterne J.A.C., Bartlett C., Juni P., Egger M. Do we need comprehensive literature searches? A study of publication and language bias in meta-analyses of controlled trials. 3rd Symposium on Systematic Reviews: Beyond the Basics. Oxford; 2000.

[19] Moher D., Pham B., Klassen T.P., Shulz K.F., Berlin J.A., Jadad A.R., et al. What contributions do languages other than English make on the results of meta-analyses? Journal of Clinical Epidemiology 2000; 53: 964-72. 
[20] Moscati R., Jehle D., Ellis D., Fiorello A., Landi M. Positive-outcome bias: Comparison of emergency medicine and general medicine literatures. Academic Emergency Medicine 1994; 1: 267-271.

[21] Pittler M.H., Abbot N.C., Harkness E.F., Ernst E. Location bias in controlled clinical trials of complementary/alternative therapies. Journal of Clinical Epidemiology 2000; 53: 485-489.

[22] Vickers A., Goyal N., Harland R., Rees R. Do certain countries produce only positive results? A systematic review of controlled trials. Controlled Clinical Trials 1998; 19: $159-166$.

[23] Sterne J.A.C., Egger M., Smith G.D. Investigating and dealing with publication and other biases. In: Egger M., Smith G.D., Altman D.G., eds. Systematic reviews in health care: Meta-analysis in context. London: BMJ Books; 2001.

[24] Sutton A.J., Duval S.J., Tweedie R.L., Abrams K.R., Jones D.R. Empirical assessment of effect of publication bias on meta-analyses. BMJ 2000; 320: 1574-1577.

[25] Lipsey M.W., Wilson D.B. Practical Meta-analysis. Thousand Oaks, CA: SAGE Publications; 2001.

[26] Borenstein M., Hedges L.V., Higgins J., Rothstein H. Comprehensive Meta-analysis 2.0. Englewood, NJ: Biostat, Inc.; 2007.

[27] Hedges L.V., Olkin I. Statistical methods for meta-analysis. Orlando, Florida: Academic Press; 1985.

[28] Higgins J.P., Thompson S.G., Deeks J.J., Altman D.G. Measuring inconsistency in metaanalyses. BMJ 2003; 327: 557-60. 
[29] Hunter J.E., Schmidt F.L. Methods of meta-analysis: Correcting error and bias in research findings. Newbury Park, CA: SAGE Publications; 1990.

[30] Rush B., Steinberg M., Brook R. Relationships among alcohol availability, alcohol consumption and alcohol-related damage in the province of Ontario and the State of Michigan. Advances in Substance Abuse 1986; 5: 33-45.

[31] Blalock, Jr. H.M. Causal inferences in nonexperimental research. New York: W.W. Norton \& Company, Inc.; 1964.

[32] Cohen J. Statistical power analysis for the behavioral sciences. Orlando, FL: Academic Press; 1977.

[33] Lipsey M.W., Wilson D.B. The efficacy of psychological educational and behavioral treatment: Confirmation from meta-analysis. American Psychologist 1993; 48: 1181-209.

[34] Midianik L.T., Chaloupka F., Saitz R., Toomey T.L., Fellows J.L., Landen V.M., et al. Alcohol-attributable deaths and years of potential life lost-United States, 2001. MMWR 2004; 53: 866-70.

[35] World Health Organization. Global status report on alcohol 2004. Geneva: Department of Mental Health and Substance Abuse, World Health Organization; 2004.

[36] Hingson R., Kenkel D.S. Social health and economic consequences of underage drinking. In: Bonnie R.J., O'Connell M.E., eds. Reducing underage drinking: A collective responsibility Washington, D.C.: National Academies Press; 2004.

[37] NIAAA. Five year strategic plan, FY07-011: Alcohol across the lifespan. Bethesda, MD: National Institute on Alcohol Abuse and Alcoholism, National Institutes of Health; 2006.

[38] Smith G.S., Branas C.C., Miller T.R. Fatal nontraffic injuries involving alcohol: A metaanalysis. Annals of Emergency Medicine 1999; 33: 659-68. 
Table 1: Effects of Price on Alcohol Consumption

\begin{tabular}{|c|c|c|c|c|c|}
\hline Study & $\boldsymbol{r}$ & $\begin{array}{c}\text { lower } \\
\text { Cl }\end{array}$ & $\begin{array}{c}\text { upper } \\
\text { Cl }\end{array}$ & $z$ & $p$ \\
\hline Bask, 2004 & -0.72 & -0.83 & -0.53 & -5.83 & 0.00 \\
\hline Bishai, 2005 & -0.03 & -0.04 & -0.02 & -4.63 & 0.00 \\
\hline Blake, 1997 & -0.57 & -0.75 & -0.32 & -3.96 & 0.00 \\
\hline Bourgeois, 1979 & -0.06 & -0.18 & 0.07 & -0.85 & 0.40 \\
\hline Brinkley, 1999 & 0.03 & -0.27 & 0.33 & 0.22 & 0.83 \\
\hline Clements, 1983 & -0.71 & -0.87 & -0.42 & -3.94 & 0.00 \\
\hline Clements, 1991 & -0.84 & -0.92 & -0.70 & -6.63 & 0.00 \\
\hline Clements, 1997 & -0.60 & -0.81 & -0.23 & -2.97 & 0.00 \\
\hline Duffy, 1987 & -0.58 & -0.81 & -0.20 & -2.84 & 0.00 \\
\hline Holm, 1992 & 0.01 & -0.39 & 0.40 & 0.05 & 0.96 \\
\hline Leppanen, 2001 & -0.64 & -0.84 & -0.30 & -3.29 & 0.00 \\
\hline Levy, 1983 & -0.62 & -0.78 & -0.38 & -4.45 & 0.00 \\
\hline McGuinness, 1980 & -0.39 & -0.71 & 0.07 & -1.69 & 0.09 \\
\hline Nelson, 1995 & 0.03 & -0.35 & 0.41 & 0.15 & 0.88 \\
\hline Nelson, 1997 & -0.41 & -0.59 & -0.19 & -3.45 & 0.00 \\
\hline Nelson, 2003 & -0.14 & -0.22 & -0.05 & -3.01 & 0.00 \\
\hline Ruhm, 1995 & -0.40 & -0.46 & -0.33 & -10.69 & 0.00 \\
\hline Rush, 1986 & -0.96 & -0.98 & -0.92 & -9.95 & 0.00 \\
\hline Selvanathan, 1988 & -0.61 & -0.79 & -0.33 & -3.77 & 0.00 \\
\hline Smart, 1998 & -0.83 & -0.93 & -0.60 & -4.72 & 0.00 \\
\hline Treno, 1993 & 0.07 & -0.26 & 0.38 & 0.40 & 0.69 \\
\hline Wilkinson, 1987 & -0.10 & -0.23 & 0.03 & -1.48 & 0.14 \\
\hline Young, 2003 & -0.12 & -0.18 & -0.05 & -3.25 & 0.00 \\
\hline Zhang, 1999 & -0.57 & -0.73 & -0.36 & -4.53 & 0.00 \\
\hline AGGREGATE-LEVEL STUDIES & -0.44 & -0.54 & -0.34 & -7.55 & 0.00 \\
\hline Cameron, 2001 & -0.04 & -0.06 & -0.02 & -3.74 & 0.00 \\
\hline Chaloupka, 1996 & -0.02 & -0.05 & 0.01 & -1.31 & 0.19 \\
\hline Chaloupka, 1997 & -0.03 & -0.04 & -0.01 & -4.03 & 0.00 \\
\hline Cook, 1993 & -0.09 & -0.16 & -0.01 & -2.35 & 0.02 \\
\hline Cook, 1994 & -0.04 & -0.08 & -0.01 & -2.25 & 0.02 \\
\hline Dee, 1999 & -0.05 & -0.09 & -0.01 & -2.29 & 0.02 \\
\hline DiNardo, 2001 & 0.00 & -0.01 & 0.00 & -0.29 & 0.77 \\
\hline Farrell, 2003 & -0.01 & -0.02 & 0.00 & -1.96 & 0.05 \\
\hline French, 2006 & -0.03 & -0.09 & 0.03 & -0.99 & 0.32 \\
\hline Gao, 1995 & -0.08 & -0.11 & -0.05 & -5.53 & 0.00 \\
\hline Gius, 2005 & 0.00 & -0.03 & 0.03 & -0.12 & 0.90 \\
\hline Grossman, 1998 & -0.02 & -0.04 & -0.01 & -3.18 & 0.00 \\
\hline Grossman, 1999 & -0.04 & -0.05 & -0.03 & -13.75 & 0.00 \\
\hline Hamilton, 1997 & 0.00 & -0.04 & 0.05 & 0.08 & 0.93 \\
\hline Harris, 2006 & -0.02 & -0.03 & 0.00 & -1.58 & 0.11 \\
\hline Henderson, 2004 & -0.11 & -0.18 & -0.05 & -3.40 & 0.00 \\
\hline Kenkel, 1996 & -0.06 & -0.07 & -0.04 & -6.38 & 0.00 \\
\hline Laixuthai, 1993 & -0.05 & -0.06 & -0.03 & -5.42 & 0.00 \\
\hline Lyon, 1995 & -0.05 & -0.11 & 0.01 & -1.71 & 0.09 \\
\hline Manning, 1995 & -0.01 & -0.03 & 0.00 & -1.79 & 0.07 \\
\hline Pacula, 1998 & -0.02 & -0.05 & 0.00 & -1.95 & 0.05 \\
\hline Sloan, 1995 & 0.09 & 0.08 & 0.10 & 17.73 & 0.00 \\
\hline Sutton, 1995 & -0.04 & -0.06 & -0.01 & -3.06 & 0.00 \\
\hline Wang, 1996 & -0.09 & -0.15 & -0.03 & -3.00 & 0.00 \\
\hline Waters, 1995 & -0.18 & -0.20 & -0.16 & -16.73 & 0.00 \\
\hline Williams, 2003 & -0.01 & -0.02 & 0.00 & -2.03 & 0.04 \\
\hline Williams, 2004 & -0.01 & -0.02 & 0.00 & -1.67 & 0.09 \\
\hline Williams, 2005 & 0.02 & 0.00 & 0.03 & 2.62 & 0.01 \\
\hline Yen, 1994 & -0.10 & -0.13 & -0.07 & -6.64 & 0.00 \\
\hline Zhao, 2004 & 0.00 & -0.01 & 0.01 & 0.17 & 0.87 \\
\hline INDIVIDUAL-LEVEL STUDIES & -0.03 & -0.05 & -0.02 & -4.27 & 0.00 \\
\hline Total w/o Rush, 1986 & -0.06 & -0.08 & -0.04 & -7.56 & 0.00 \\
\hline Total & -0.06 & -0.08 & -0.05 & -7.86 & 0.00 \\
\hline
\end{tabular}


Mean Elasticity: $-0.51 \mathrm{n}=91$

Table 2 Effects of Price on Beer Consumption

\begin{tabular}{|c|c|c|c|c|c|}
\hline Study & $r$ & lower $\mathrm{Cl}$ & upper Cl & $Z$ & $p$ \\
\hline Adrian, 1987 & -0.30 & -0.58 & 0.04 & -1.72 & 0.08 \\
\hline Asplund, 2007 & -0.23 & -0.24 & -0.22 & -37.85 & 0.00 \\
\hline Beard, 1997 & -0.20 & -0.32 & -0.07 & -3.02 & 0.00 \\
\hline Bentzen, 1999 & -0.02 & -0.35 & 0.32 & -0.11 & 0.91 \\
\hline Blake, 1997 & -0.17 & -0.46 & 0.15 & -1.03 & 0.30 \\
\hline Bourgeois, 1979 & -0.11 & -0.23 & 0.02 & -1.71 & 0.09 \\
\hline Clements, 1983 & -0.61 & -0.82 & -0.27 & -3.18 & 0.00 \\
\hline Clements, 1991 & -0.36 & -0.63 & -0.01 & -2.03 & 0.04 \\
\hline Duffy, 1982 & -0.04 & -0.33 & 0.26 & -0.24 & 0.81 \\
\hline Duffy, 1983 & 0.17 & -0.08 & 0.40 & 1.32 & 0.19 \\
\hline Duffy, 1987 & -0.54 & -0.79 & -0.14 & -2.55 & 0.01 \\
\hline Freeman, 2000 & -0.04 & -0.09 & 0.01 & -1.68 & 0.09 \\
\hline Godfrey, 1988 & -0.16 & -0.52 & 0.25 & -0.76 & 0.45 \\
\hline Hogarty, 1972 & -0.21 & -0.36 & -0.05 & -2.58 & 0.01 \\
\hline Holm, 1992 & 0.11 & -0.13 & 0.33 & 0.89 & 0.37 \\
\hline Johnson, 1974 & -0.23 & -0.37 & -0.08 & -2.96 & 0.00 \\
\hline Johnson, 1977 & -0.26 & -0.41 & -0.10 & -3.15 & 0.00 \\
\hline Johnson, 1992 & -0.12 & -0.23 & 0.00 & -1.94 & 0.05 \\
\hline Jones, 1989 & -0.29 & -0.48 & -0.07 & -2.60 & 0.01 \\
\hline Kubik, 2002 & -0.09 & -0.14 & -0.04 & -3.25 & 0.00 \\
\hline Kuo, 2003 & -0.33 & -0.35 & -0.32 & -36.20 & 0.00 \\
\hline Lee, 1992 & -0.43 & -0.68 & -0.09 & -2.46 & 0.01 \\
\hline Mast, 1999 & -0.07 & -0.16 & 0.03 & -1.36 & 0.17 \\
\hline Nelson, 1990 & -0.34 & -0.57 & -0.06 & -2.39 & 0.02 \\
\hline Nelson, 1995 & 0.40 & 0.03 & 0.68 & 2.09 & 0.04 \\
\hline Nelson, 1997 & -0.29 & -0.50 & -0.05 & -2.37 & 0.02 \\
\hline Nelson, 2003 & -0.21 & -0.29 & -0.12 & -4.69 & 0.00 \\
\hline Norstrom, 2005 & -0.39 & -0.63 & -0.09 & -2.51 & 0.01 \\
\hline Ornstein, 1985 & -0.15 & -0.28 & -0.01 & -2.14 & 0.03 \\
\hline Saffer, 1989 & -0.15 & -0.28 & -0.01 & -2.06 & 0.04 \\
\hline Salisu, 1997 & -0.18 & -0.34 & 0.00 & -1.99 & 0.05 \\
\hline Selvanathan, 1988 & -0.34 & -0.62 & 0.02 & -1.85 & 0.06 \\
\hline Selvanathan, 1991 & -0.33 & -0.63 & 0.07 & -1.61 & 0.11 \\
\hline Thom, 1984 & 0.55 & 0.31 & 0.72 & 4.09 & 0.00 \\
\hline Trolldal, 2005 & -0.04 & -0.11 & 0.03 & -1.14 & 0.26 \\
\hline Uri, 1986 & -0.30 & -0.53 & -0.02 & -2.11 & 0.03 \\
\hline Walsh, 1970 & 0.03 & -0.49 & 0.53 & 0.11 & 0.92 \\
\hline Walsh, 1982 & -0.45 & -0.74 & -0.01 & -1.99 & 0.05 \\
\hline Wette, 1993 & -0.39 & -0.65 & -0.04 & -2.20 & 0.03 \\
\hline Zhang, 1999 & -0.33 & -0.55 & -0.06 & -2.36 & 0.02 \\
\hline AGGREGATE-LEVEL & -0.17 & -0.22 & -0.12 & -6.91 & 0.00 \\
\hline Angulo, 2001 & -0.02 & -0.03 & 0.00 & -1.96 & 0.05 \\
\hline Coate, 1988 & -0.04 & -0.08 & 0.01 & -1.51 & 0.13 \\
\hline Gao, 1995 & -0.03 & -0.06 & 0.00 & -2.12 & 0.03 \\
\hline Grossman, 1987 & -0.06 & -0.13 & 0.01 & -1.58 & 0.11 \\
\hline Heien, 1989 & -0.01 & -0.02 & 0.01 & -0.78 & 0.44 \\
\hline Rabow, 1982 & -0.06 & -0.18 & 0.06 & -1.00 & 0.32 \\
\hline Wang, 1996 & -0.58 & -0.62 & -0.54 & -22.60 & 0.00 \\
\hline INDIVIDUAL-LEVEL & -0.12 & -0.22 & -0.02 & -2.37 & 0.02 \\
\hline Total w/o Thom, 1984 & -0.18 & -0.23 & -0.12 & -6.37 & 0.00 \\
\hline Total & -0.17 & -0.22 & -0.11 & -5.93 & 0.00 \\
\hline \multicolumn{6}{|c|}{ Mean Elasticity: $-0.46 n=105$} \\
\hline
\end{tabular}


Table 3: Effects of Price on Wine Consumption

\begin{tabular}{|c|c|c|c|c|c|}
\hline Study & $r$ & lower $\mathbf{C l}$ & upper $\mathrm{Cl}$ & $\boldsymbol{Z}$ & $p$ \\
\hline Adrian, 1987 & -0.48 & -0.70 & -0.18 & -2.95 & 0.00 \\
\hline Asplund, 2007 & -0.10 & -0.11 & -0.09 & -15.91 & 0.00 \\
\hline Bentzen, 1999 & -0.38 & -0.63 & -0.06 & -2.27 & 0.02 \\
\hline Blake, 1997 & 0.01 & -0.30 & 0.32 & 0.06 & 0.96 \\
\hline Bourgeois, 1979 & 0.04 & -0.08 & 0.17 & 0.69 & 0.49 \\
\hline Clements, 1983 & -0.47 & -0.74 & -0.07 & -2.27 & 0.02 \\
\hline Clements, 1991 & -0.36 & -0.63 & -0.01 & -2.03 & 0.04 \\
\hline Duffy, 1982 & -0.48 & -0.67 & -0.23 & -3.49 & 0.00 \\
\hline Duffy, 1983 & -0.23 & -0.45 & 0.02 & -1.80 & 0.07 \\
\hline Duffy, 1987 & -0.67 & -0.86 & -0.34 & -3.47 & 0.00 \\
\hline Godfrey, 1988 & -0.42 & -0.70 & -0.03 & -2.12 & 0.03 \\
\hline Holm, 1992 & -0.30 & -0.49 & -0.07 & -2.57 & 0.01 \\
\hline Johnson, 1974 & -0.37 & -0.50 & -0.23 & -4.86 & 0.00 \\
\hline Johnson, 1977 & -0.46 & -0.58 & -0.32 & -5.85 & 0.00 \\
\hline Johnson, 1992 & -0.31 & -0.41 & -0.20 & -5.25 & 0.00 \\
\hline Jones, 1989 & -0.41 & -0.58 & -0.21 & -3.82 & 0.00 \\
\hline Labys, 1976 & -0.51 & -0.79 & -0.06 & -2.20 & 0.03 \\
\hline Nelson, 1990 & -0.45 & -0.65 & -0.19 & -3.27 & 0.00 \\
\hline Nelson, 1995 & 0.34 & -0.04 & 0.64 & 1.76 & 0.08 \\
\hline Nelson, 1997 & -0.28 & -0.49 & -0.04 & -2.25 & 0.02 \\
\hline Nelson, 2003 & -0.24 & -0.32 & -0.15 & -5.30 & 0.00 \\
\hline Norstrom, 2005 & -0.27 & -0.54 & 0.04 & -1.71 & 0.09 \\
\hline Saffer, 1989 & 0.08 & -0.06 & 0.22 & 1.12 & 0.26 \\
\hline Salisu, 1997 & -0.20 & -0.36 & -0.02 & -2.22 & 0.03 \\
\hline Selvanathan, 1988 & -0.70 & -0.84 & -0.45 & -4.55 & 0.00 \\
\hline Selvanathan, 1991 & -0.41 & -0.69 & -0.02 & -2.06 & 0.04 \\
\hline Thom, 1984 & -0.06 & -0.35 & 0.23 & -0.43 & 0.67 \\
\hline Trolldal, 2005 & 0.00 & -0.07 & 0.08 & 0.09 & 0.93 \\
\hline Uri, 1986 & -0.66 & -0.79 & -0.47 & -5.47 & 0.00 \\
\hline Walsh, 1982 & -0.52 & -0.78 & -0.10 & -2.39 & 0.02 \\
\hline Wette, 1993 & -0.49 & -0.72 & -0.17 & -2.90 & 0.00 \\
\hline Zhang, 1999 & -0.35 & -0.57 & -0.08 & -2.54 & 0.01 \\
\hline AGGREGATE-Level & -0.30 & -0.36 & -0.23 & -8.03 & 0.00 \\
\hline Angulo, 2001 & -0.02 & -0.03 & 0.00 & -1.96 & 0.05 \\
\hline Gao, 1995 & -0.01 & -0.04 & 0.02 & -0.81 & 0.42 \\
\hline Grossman, 1987 & -0.03 & -0.10 & 0.04 & -0.86 & 0.39 \\
\hline Heien, 1989 & -0.02 & -0.04 & -0.01 & -2.75 & 0.01 \\
\hline Rabow, 1982 & 0.01 & -0.10 & 0.13 & 0.23 & 0.82 \\
\hline Wang, 1996 & -0.64 & -0.67 & -0.61 & -25.72 & 0.00 \\
\hline INDIVIDUAL-LEVEL & -0.14 & -0.26 & -0.01 & -2.08 & 0.04 \\
\hline Total & -0.25 & -0.30 & -0.19 & -8.86 & 0.00 \\
\hline Mean Elasticity: -0.69 & $n=93$ & & & & \\
\hline
\end{tabular}


Table 4: Effects of Price on Distilled Spirits Consumption

\begin{tabular}{|c|c|c|c|c|c|}
\hline Study & $r$ & lower $\mathrm{Cl}$ & upper $\mathbf{C l}$ & $Z$ & $p$ \\
\hline Adrian, 1987 & -0.23 & -0.52 & 0.12 & -1.30 & 0.19 \\
\hline Asplund, 2007 & -0.28 & -0.29 & -0.27 & -45.49 & 0.00 \\
\hline Baltagi, 1990 & -0.30 & -0.54 & -0.01 & -2.04 & 0.04 \\
\hline Baltagi, 1995 & -0.07 & -0.13 & 0.00 & -2.10 & 0.04 \\
\hline Baltagi, 2002 & -0.08 & -0.13 & -0.03 & -3.01 & 0.00 \\
\hline Beard, 1997 & -0.29 & -0.41 & -0.17 & -4.55 & 0.00 \\
\hline Bentzen, 1999 & -0.42 & -0.66 & -0.10 & -2.54 & 0.01 \\
\hline Blake, 1997 & -0.18 & -0.47 & 0.14 & -1.12 & 0.26 \\
\hline Bourgeois, 1979 & 0.17 & 0.04 & 0.29 & 2.57 & 0.01 \\
\hline Clements, 1983 & -0.71 & -0.87 & -0.42 & -3.94 & 0.00 \\
\hline Clements, 1991 & -0.77 & -0.88 & -0.58 & -5.54 & 0.00 \\
\hline Cook, 1982 & -0.19 & -0.27 & -0.10 & -4.17 & 0.00 \\
\hline Duffy, 1982 & -0.59 & -0.75 & -0.37 & -4.54 & 0.00 \\
\hline Duffy, 1983 & -0.43 & -0.61 & -0.20 & -3.56 & 0.00 \\
\hline Duffy, 1987 & -0.54 & -0.79 & -0.15 & -2.58 & 0.01 \\
\hline Godfrey, 1988 & -0.74 & -0.88 & -0.49 & -4.49 & 0.00 \\
\hline Goel, 1995 & -0.12 & -0.19 & -0.05 & -3.47 & 0.00 \\
\hline Hoadley, 1984 & -0.24 & -0.48 & 0.02 & -1.78 & 0.07 \\
\hline Holm, 1992 & -0.08 & -0.30 & 0.15 & -0.68 & 0.50 \\
\hline Johnson, 1974 & -0.48 & -0.59 & -0.35 & -6.57 & 0.00 \\
\hline Johnson, 1977 & -0.59 & -0.69 & -0.47 & -7.91 & 0.00 \\
\hline Johnson, 1992 & 0.01 & -0.11 & 0.12 & 0.10 & 0.92 \\
\hline Jones, 1989 & -0.52 & -0.66 & -0.33 & -5.01 & 0.00 \\
\hline McCornac, 1984 & -0.18 & -0.35 & 0.00 & -1.99 & 0.05 \\
\hline Musgrave, 1988 & -0.97 & -0.99 & -0.90 & -6.08 & 0.00 \\
\hline Nelson, 1990 & -0.34 & -0.57 & -0.07 & -2.44 & 0.01 \\
\hline Nelson, 1995 & 0.48 & 0.13 & 0.73 & 2.58 & 0.01 \\
\hline Nelson, 1997 & -0.48 & -0.65 & -0.27 & -4.17 & 0.00 \\
\hline Nelson, 2003 & 0.02 & -0.07 & 0.10 & 0.33 & 0.74 \\
\hline Norstrom, 2005 & 0.06 & -0.26 & 0.36 & 0.34 & 0.74 \\
\hline Ornstein, 1985 & -0.33 & -0.45 & -0.21 & -4.99 & 0.00 \\
\hline Saffer, 1989 & -0.31 & -0.43 & -0.18 & -4.49 & 0.00 \\
\hline Salisu, 1997 & -0.40 & -0.54 & -0.24 & -4.69 & 0.00 \\
\hline Selvanathan, 1988 & -0.51 & -0.73 & -0.19 & -2.96 & 0.00 \\
\hline Selvanathan, 1991 & -0.42 & -0.70 & -0.04 & -2.14 & 0.03 \\
\hline Skog, 2006 & -0.76 & -0.90 & -0.50 & -4.28 & 0.00 \\
\hline Smith, 1976 & -0.50 & -0.69 & -0.25 & -3.61 & 0.00 \\
\hline Thom, 1984 & 0.31 & 0.02 & 0.55 & 2.11 & 0.04 \\
\hline Trolldal, 2005 & -0.07 & -0.14 & 0.00 & -2.06 & 0.04 \\
\hline Uri, 1986 & -0.29 & -0.52 & -0.01 & -2.05 & 0.04 \\
\hline Wales, 1968 & -0.21 & -0.48 & 0.10 & -1.34 & 0.18 \\
\hline Walsh, 1970 & -0.29 & -0.70 & 0.26 & -1.03 & 0.30 \\
\hline Walsh, 1982 & -0.58 & -0.81 & -0.18 & -2.71 & 0.01 \\
\hline Wette, 1993 & -0.04 & -0.38 & 0.32 & -0.20 & 0.84 \\
\hline Zhang, 1999 & -0.03 & -0.30 & 0.25 & -0.19 & 0.85 \\
\hline AGGREGATE-LEVEL & -0.29 & -0.34 & -0.23 & -9.23 & 0.00 \\
\hline Angulo, 2001 & -0.02 & -0.03 & 0.00 & -1.96 & 0.05 \\
\hline Gao, 1995 & -0.02 & -0.05 & 0.01 & -1.19 & 0.23 \\
\hline Grossman, 1987 & -0.07 & -0.14 & 0.00 & -1.87 & 0.06 \\
\hline Heien, 1989 & -0.02 & -0.04 & 0.00 & -2.53 & 0.01 \\
\hline Rabow, 1982 & -0.03 & -0.15 & 0.10 & -0.43 & 0.67 \\
\hline Wang, 1996 & -0.40 & -0.45 & -0.35 & -14.48 & 0.00 \\
\hline INDIVIDUAL-LEVEL & -0.10 & -0.17 & -0.02 & -2.52 & 0.01 \\
\hline Total w/o Musgrave, 1988 & -0.24 & -0.29 & -0.19 & -8.82 & 0.00 \\
\hline Total & -0.25 & -0.30 & -0.20 & -9.15 & 0.00 \\
\hline Mean Elasticity $-0.80 n=103$ & & & & & \\
\hline
\end{tabular}


Table 5: Effects of Price on Heavy Alcohol Use (all individual-level studies)

\begin{tabular}{|c|c|c|c|c|c|}
\hline \multirow[b]{2}{*}{ Study } & \multicolumn{3}{|c|}{ lower } & \multirow[b]{2}{*}{$\boldsymbol{Z}$} & \multirow[b]{2}{*}{$p$} \\
\hline & $\boldsymbol{r}$ & $\mathrm{Cl}$ & upper $\mathrm{Cl}$ & & \\
\hline Chaloupka, 1996 & -0.01 & -0.04 & 0.02 & -0.77 & 0.44 \\
\hline Chaloupka, 1997 & -0.01 & -0.03 & 0.00 & -2.14 & 0.03 \\
\hline Cook, 1994 & -0.05 & -0.09 & 0.00 & -2.12 & 0.03 \\
\hline Keng, 2006 & -0.01 & -0.03 & 0.00 & -2.70 & 0.01 \\
\hline Kenkel, 1993 & -0.06 & -0.11 & -0.02 & -2.72 & 0.01 \\
\hline Kenkel, 1996 & 0.01 & -0.01 & 0.02 & 0.65 & 0.51 \\
\hline Laixuthai, 1993 & -0.02 & -0.04 & 0.00 & -2.45 & 0.01 \\
\hline Powell, 2002 & -0.02 & -0.04 & 0.00 & -2.58 & 0.01 \\
\hline Sloan, 1995 & -0.03 & -0.05 & 0.00 & -2.32 & 0.02 \\
\hline Stout, 2000 & 0.01 & 0.00 & 0.02 & 2.69 & 0.01 \\
\hline Total & -0.01 & -0.03 & 0.00 & -2.54 & 0.01 \\
\hline Mean Elasticity: $-0.28 \quad n=10$ & & & & & \\
\hline
\end{tabular}


Figure 1. Effects of Price on Alcohol Consumption: Aggregate-level Studies

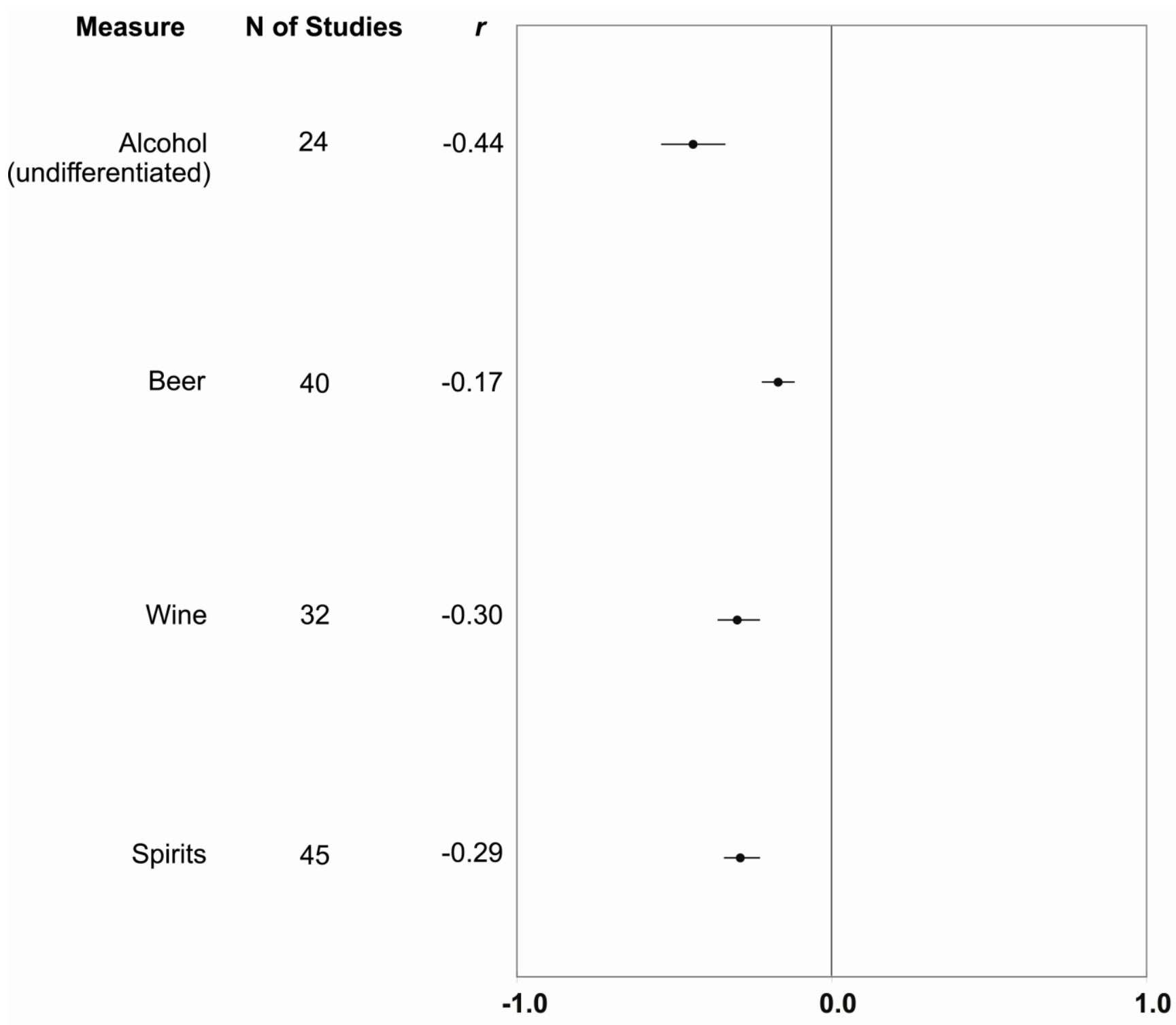


Figure 2. Effects of Price on Alcohol Consumption: Individual-level Studies

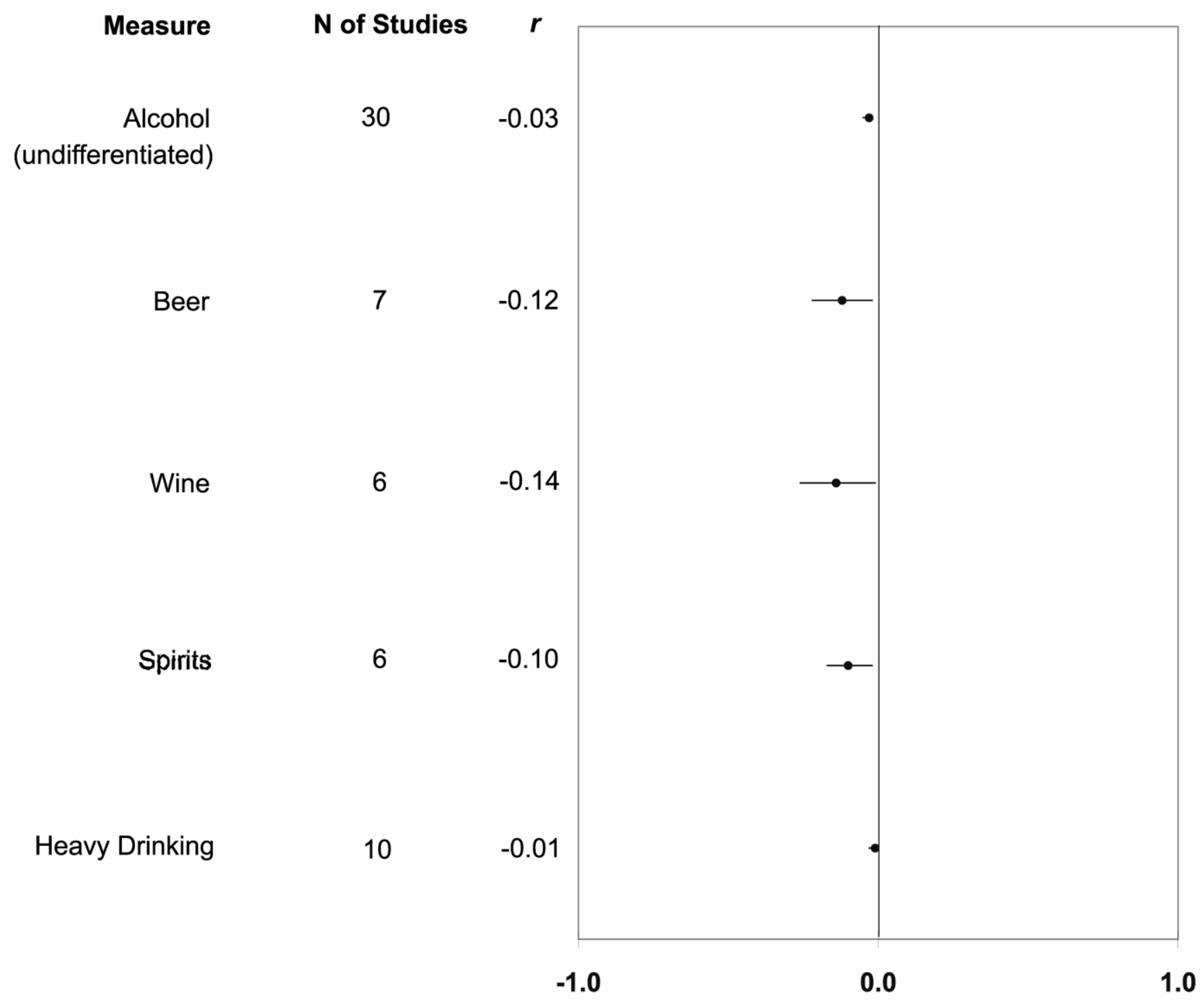




\section{APPENDIX: STUDIES INCLUDED IN META-ANALYSIS}

Adrian M., Ferguson B.S. Demand for domestic and imported alcohol in Canada. Applied Economics. 1987; 19: 531-40.

Angulo A.M., Gil J.M., Gracia A. The demand for alcoholic beverages in Spain. Agricultural Economics. 2001; 26: 71-83.

Asplund M., Friberg R., Wilander F. Demand and distance: Evidence on cross-border shopping. Journal of Public Economics. 2007; 91: 141-57.

Baltagi B.H., Goel R.K. Quasi-experimental price elasticity of liquor demand in the UnitedStates - 1960-83. American Journal of Agricultural Economics. 1990; 72: 451-4.

Baltagi B.H., Griffin J.M. A dynamic demand model for liquor - the case for pooling. Review of Economics and Statistics. 1995; 77: 545-54.

Baltagi B.H., Griffin J.M. Rational addiction to alcohol: panel data analysis of liquor consumption. Health Economics. 2002; 11: 485-91.

Bask M., Melkersson M. Rationally addicted to drinking and smoking? Applied Economics. 2004; 36: 373-81.

Beard T.R., Gant P.A., Saba R.P. Border-crossing sales, tax avoidance, and state tax policies: An application to alcohol. Southern Economic Journal. 1997; 64: 293-306.

Bentzen J., Eriksson T., Smith V. Rational addiction and alcohol consumption: evidence from the Nordic countries. Journal of Consumer Policy. 1999; 22: 257-79.

Bishai D.M., Mercer D., Tapales A. Can government policies help adolescents avoid risky behavior? Preventive Medicine. 2005; 40: 197-202.

Blake D., Nied A. The demand for alcohol in the United Kingdom. Applied Economics. 1997; 29: $1655-72$. 
Bourgeois J.C., Barnes J.G. Does advertising increase alcohol-consumption. Journal of Advertising Research. 1979; 19: 19-29.

Brinkley G.L. The causal relationship between socioeconomic factors and alcohol consumption: A Granger-causality time series analysis, 1950-1993. Journal of Studies on Alcohol. 1999; 60: 759-68.

Cameron L., Williams J. Cannabis, alcohol and cigarettes: Substitutes or complements? Economic Record. 2001; 77: 19-34.

Chaloupka F.J., Laixuthai A. Do youths substitute alcohol and marijuana? Some econometric evidence. Eastern Economic Journal. 1997; 23: 253-76.

Chaloupka F.J., Wechsler H. Binge drinking in college: The impact of price, availability, and alcohol control policies. Contemporary Economic Policy. 1996; 14: 112-24.

Clements K.W., Johnson L.W. The demand for beer, wine, and spirits - a systemwide analysis. Journal of Business. 1983; 56: 273-304.

Clements K.W., Selvanathan S. The economic-determinants of alcohol-consumption. Australian Journal of Agricultural Economics. 1991; 35: 209-31.

Clements K.W., Yang W., Zheng S.W. Is utility additive? The case of alcohol. Applied Economics. 1997; 29: 1163-7.

Coate D., Grossman M. Effects of alcoholic beverage prices and legal drinking ages on youth alcohol-use. Journal of Law \& Economics. 1988; 31: 145-71.

Cook P.J. Alcohol taxes as a public-health measure. British Journal of Addiction. 1982; 77: 24550.

Cook P.J., Moore M.J. Violence reduction through restrictions on alcohol availability. Alcohol Health and Research World. 1993; 17: 151-6. 
Cook P.J., Moore M.J. This tax's for you- the case for higher beer taxes. National Tax Journal. 1994; 47: 559-73.

Dee T.S. State alcohol policies, teen drinking and traffic fatalities. Journal of Public Economics. 1999; 72: 289-315.

DiNardo J., Lemieux T. Alcohol, marijuana, and American youth: the unintended consequences of government regulation. Journal of Health Economics. 2001; 20: 991-1010.

Duffy M. The influences of prices, consumer incomes and advertising upon the demand for alcoholic drink in the United-Kingdom - an econometric study. British Journal on Alcohol and Alcoholism. 1981; 16: 200-8.

Duffy M. The demand for alcoholic drink in the United-Kingdom, 1963-78. Applied Economics. 1983; 15: 125-40.

Duffy M.H. Advertising and the inter-product distribution of demand: a Rotterdam model approach. European Economic Review. 1987; 31: 1051-1070.

Farrell S., Manning W.G., Finch M.D. Alcohol dependence and the price of alcoholic beverages. Journal of Health Economics. 2003; 22: 117-47.

Freeman D.G. Alternative panel estimates of alcohol demand, taxation, and the business cycle. Southern Economic Journal. 2000; 67: 325-44.

French M.T., Brown-Taylor D., Bluthenthal R.N. Price elasticity of demand for malt liquor beer: Findings from a US pilot study. Social Science \& Medicine. 2006; 62: 2101-11.

Gao X.M., Wailes E.J., Cramer G.L. A microeconometric model analysis of U.S. consumer demand for alcoholic beverages. Applied Economics. 1995; 27: 59-69.

Gius M.P. An estimate of the effects of age, taxes, and other socioeconomic variables on the alcoholic beverage demand of young adults. Social Science Journal. 2005; 42: 13-24. 
Godfrey C. Licensing and the demand for alcohol. Applied Economics. 1988; 20: 1541-58.

Goel R.K., Morey M.J. The interdependence of cigarette and liquor demand. Southern Economic Journal. 1995; 62: 451-9.

Grossman M., Chaloupka F.J., Sirtalan I. An empirical analysis of alcohol addiction: Results from the monitoring the future panels. Economic Inquiry. 1998; 36: 39-48.

Grossman M., Coate D., Arluck G.M. Price sensitivity of alcoholic beverages in the United States. Advances in Substance Abuse. 1987; 1: 169-98.

Grossman M., Markowitz S. Alcohol Regulation and Violence on College Campuses. (Report No. Working Paper 7129). Cambridge, MA: National Bureau of Economic Research; 1999.

Hamilton V., Hamilton B.H. Alcohol and earnings: Does drinking yield a wage premium? Canadian Journal of Economics-Revue Canadienne D Economique. 1997; 30: 135-51.

Harris M.N., Ramful P., Zhao X.Y. An ordered generalised extreme value model with application to alcohol consumption in Australia. Journal of Health Economics. 2006; 25: $782-801$.

Heien D., Pompelli G. The demand for alcoholic beverages - economic and demographic effects. Southern Economic Journal. 1989; 55: 759-70.

Henderson C., Liu X.H., Roux A.V.D., Link B.G., Hasin D. The effects of US state income inequality and alcohol policies on symptoms of depression and alcohol dependence. Social Science \& Medicine. 2004; 58: 565-75.

Hoadley J.F., Fuchs B.C., Holder H.D. The effect of alcohol beverage restrictions on consumption - a 25-year longitudinal analysis. American Journal of Drug and Alcohol Abuse. 1984; 10: 375-401. 
Hogarty T.F., Elzinga K.G. Demand for beer. Review of Economics and Statistics. 1972; 54: 195-8.

Holm P., Suoniemi I. Empirical application of optimal commodity tax theory to taxation of alcoholic beverages. Scandinavian Journal of Economics. 1992; 94: 85-101.

Johnson J.A., Oksanen E.H. Socio-economic determinants of consumption of alcoholic beverages. Applied Economics. 1974; 6: 293-301.

Johnson J.A., Oksanen E.H. Estimation of demand for alcoholic beverages in Canada from pooled time-series and cross-sections. Review of Economics and Statistics. 1977; 59: 1138.

Johnson J.A., Oksanen E.H., Veall M.R., Fretz D. Short-run and long-run elasticities for Canadian consumption of alcoholic beverages - an error-correction mechanism cointegration approach. Review of Economics and Statistics. 1992; ;74: 64-74.

Jones A.M. A systems approach to the demand for alcohol and tobacco. Bulletin of Economic Research. 1989; 41: 85-101.

Keng S., Hufman W.E. Binge drinking and labor market success: a longitudinal study on young people. Journal of Population Economics. 2007; 20:.35-54.

Kenkel D.S. Drinking, driving, and deterrence - the effectiveness and social costs of alternative policies. Journal of Law \& Economics. 1993; 36: 877-913.

Kenkel D.S. New estimates of the optimal tax on alcohol. Economic Inquiry. 1996; 34: 296-319.

Kubik J.D., Moran J.R. Can Policy Changes be Treated as Natural Experiments? Evidence from State Excise Taxes. Syracuse, NY: Department of Economics, Syracuse University. Working Paper Series, 2002-009; 2002. 
Kuo M.C., Heeb J.L., Gmel G., Rehm J. Does price matter? The effect of decreased price on spirits consumption in Switzerland. Alcoholism-Clinical and Experimental Research. $2003 ; 27: 720-5$.

Laixuthai A., Chaloupka F.J. Youth alcohol-use and public-policy. Contemporary Policy Issues. 1993; 11: 70-81.

Lee B., Tremblay V.J. Advertising and the United-States market demand for beer. Applied Economics. 1992; 24: 69-76.

Leppänen K., Sullström R., Suoniemi I. Effects of economic factors on alcohol consumption in 14 European countries. Nordisk Alkohol and Narkotikatidskrift. 2001; 18:100-16.

Levy D., Sheflin N. New evidence on controlling alcohol-use through price. Journal of Studies on Alcohol. 1983; 44: 929-37.

Lyon A.B., Schwab R.M. Consumption taxes in a life-cycle framework. Are sin taxes regressive? Review of Economics and Statistics. 1995; 77: 389-406.

Manning W.G., Blumberg L., Moulton L.H. The demand for alcohol - the differential response to price. Journal of Health Economics. 1995; 14: 123-48.

Mast B.D., Benson B.L., Rasmussen D.W. Beer taxation and alcohol-related traffic fatalities. Southern Economic Journal. 1999; 66: 214-49.

McCornac D.C., Filante R.W. The demand for distilled spirits - an empirical-investigation. Journal of Studies on Alcohol. 1984; 45: 176-8.

McGuinness T. An econometric-analysis of total demand for alcoholic beverages in the UK, 1956-75. Journal of Industrial Economics. 1980; 29: 85-109.

Musgrave S., Stern N. Alcohol - demand and taxation under monopoly and oligopoly in SouthIndia in the 1970s. Journal of Development Economics. 1988; 28: 1-41. 
Nelson J.P. State monopolies and alcoholic beverage consumption. Journal of Regulatory Economics. 1990; 2: 83-98.

Nelson J.P. Economic and demographic factors in U.S. alcohol demand: a growth -accounting analysis. Empirical Economics. 1997; 22: 83-102.

Nelson J.P. Advertising bans, monopoly, and alcohol demand: Testing for substitution effects using state panel data. Review of Industrial Organization. 2003; 22: 1-25.

Nelson J.P., Moran J.R. Advertising and US alcoholic beverage demand - systemwide estimates. Applied Economics. 1995; 27: 1225-36.

Norstrom T. The price elasticity for alcohol in Sweden, 1984-2003. Nordisk Alkohol and Narkotikatidskrift. 2005; 22: 87-102.

Ornstein S.I., Hanssens D.M. Alcohol control laws and the consumption of distilled spirits and beer. Journal of Consumer Research. 1985; 12: 200-13.

Pacula R.L. Does increasing the beer tax reduce marijuana consumption? Journal of Health Economics. 1998; 17: 557-85.

Powell L.M., Czart C.C.U., Chaloupka F.J., Wechsler H. Binge Drinking \& Violence among College Students: Sensitivity to Correlation in the Unobservables. (ImpacTeen Research Paper Series No. 20) Chicago: University of Illinois; 2002.

Rabow J., Schwartz C., Stevens S., Watts R.K. Social psychological dimensions of alcohol availability - the relationship of perceived social obligations, price considerations, and energy expended to the frequency, amount, and type of alcoholic beverage consumed. International Journal of the Addictions. 1982; 17: 1259-71.

Ruhm C.J. Economic conditions and alcohol problems. Journal of Health Economics. 1995; 14: 583-603. 
Rush B., Steinberg M., Brook R. Relationships among alcohol availability, alcohol consumption and alcohol-related damage in the province of Ontario and the State of Michigan. Advances in Substance Abuse. 1986; 5: 33-45.

Saffer H. Alcohol Consumption and Tax Differentials Between Beer, Wine and Spirits. NBER Working Paper Series, No. 3200. Cambridge, MA; 1989.

Salisu M.A., Balasubramanyam V.N. Income and price elasticities of demand for alcoholic drinks. Applied Economics Letters. 1997; 4: 247-51.

Selvanathan E.A. Alcohol-consumption in the UK, 1955-85 - a system-wide analysis. Applied Economics. 1988; 20: 1071-86.

Selvanathan E.A. Cross-country alcohol-consumption comparison - an application of the Rotterdam demand system. Applied Economics. 1991; 23: 1613-22.

Skog O.J., Melberg H.O. Becker's rational addiction theory: an empirical test with price elasticities for distilled spirits in Denmark 1911-31. Addiction. 2006; 101: 1444-50.

Sloan F.A., Reilly B.A., Schenzler C. Effects of tort-liability and insurance on heavy drinking and drinking and driving. Journal of Law \& Economics. 1995; 38: 49-77.

Smart R.G., Mann R.E. Treatment, Alcoholics Anonymous and alcohol controls during the decrease in alcohol problems in Alberta: 1975-1993. Alcohol and Alcoholism. 1998; 33: 265-72.

Smith R.T. Legal and illegal markets for taxed goods - pure theory and an application to state government taxation of distilled spirits. Journal of Law \& Economics. 1976; 19: 393-429.

Stout E.M., Sloan F.A., Liang L., Davies H.H. Reducing harmful alcohol-related behaviors: Effective regulatory methods. Journal of Studies on Alcohol. 2000; 61: 402-12. 
Sutton M., Godfrey C. A grouped data regression approach to estimating economic and social influences on individual drinking behavior. Health Economics. 1995; 4: 237-47.

Thom D.R. The demand for alcohol in Ireland. Economic and Social Review. 1984; 15: 325-6.

Treno A.J., Parker R.N., Holder H.D. Understanding United-States alcohol-consumption with social and economic-factors - a multivariate time-series analysis, 1950-1986. Journal of Studies on Alcohol. 1993; 54: 146-56.

Trolldal B., Ponicki W. Alcohol price elasticities in control and license states in the United States, 1982-99. Addiction. 2005; 100: 1158-65.

Uri N.D. The demand for beverages and interbeverage substitution in the United States. Bulletin of Economic Research. 1986; 38: 77-85.

Wales T.J. Distilled spirits and interstate consumption effects. American Economic Review. 1968; 58: 853-63.

Walsh B.M. The demand for alcohol in the UK - a comment. Journal of Industrial Economics. 1982; 30: 439-47.

Walsh B.M., Walsh D. Economic aspects of alcohol consumption in Republic-of-Ireland. Economic and Social Review. 1970; 2: 115-38.

Wang J., Gao X.M., Wailes E.J., Cramer G.L. U.S. consumer demand for alcoholic beverages: cross-section estimation of demographic and economic effects. Review of Agricultural Economics. 1996; 18: 477-89.

Waters T.M., Sloan F.A. Why do people drink - tests of the rational addiction model. Applied Economics. 1995; 27: 727-36.

Wette H.C., Zhang J., Berg R.J., Casswell S. The effect of prices on alcohol consumption in New Zealand 1983-1991. Drug and Alcohol Review. 1993; 12: 151-8. 
Wilkinson J.T. Reducing drunken driving - which policies are most effective. Southern Economic Journal. 1987; 54: 322-34.

Williams J., Chaloupka F.J., Wechsler H. Are there differential effects of price and policy on college students' drinking intensity? Contemporary Economic Policy. 2005; 23: 78-90.

Williams, J.., Powell, L.M., \& Wechsler, H. Does alcohol consumption reduce human capital accumulation? Evidence from the College Alcohol Study. Applied Economics. 2003; 35: 1227-39.

Williams J., Pacula R.L., Chaloupka F.J., Wechsler H. Alcohol and marijuana use among college students: economic complements or substitutes? Health Economics. 2004; 13: 825-43.

Yen S.T. Cross-section estimation of United-States demand for alcoholic beverages. Applied Economics. 1994; 26: 381-92.

Young D.J., Bielinska-Kwapisz A. Alcohol consumption, beverage prices and measurement error. Journal of Studies on Alcohol. 2003; 64: 235-8.

Zhang J.F., Casswell S. The effects of real price and a change in the distribution system on alcohol consumption. Drug and Alcohol Review. 1999; 18: 371-8.

Zhao X., Harris M.N. Demand for marijuana, alcohol and tobacco: participation, levels of consumption and cross-equation correlations. The Economic Record. 2004; 80: 394-410. 